\title{
IR4.0: unmanned store apps
}

\author{
Saidatul Rahah Hamidi ${ }^{1}$, Muhammad Afiq Muhamad Yusof ${ }^{2}$, Shuhaida Mohamed Shuhidan ${ }^{3}$, \\ Shamsiah Abd Kadir ${ }^{4}$ \\ ${ }^{1,2,3}$ Faculty of Computer and Mathematical Sicences, Universiti Teknologi MARA, Malaysia \\ ${ }^{3}$ Accounting Research Institute (ARI), Universiti Teknologi MARA, Malaysia \\ ${ }^{4}$ Centre for Media and Information Warfare Studies, Universiti Teknologi MARA, Malaysia
}

\begin{tabular}{l}
\hline Article Info \\
\hline Article history: \\
Received Jun 16, 2019 \\
Revised Sep 17, 2019 \\
Accepted Oct 1, 2019 \\
\hline Keywords: \\
Industry 4.0 \\
Internet of things (IoT) \\
Retail industry \\
Smart city \\
Unmanned store
\end{tabular}

\begin{abstract}
The Internet of Things (IoT) is predicted to be one of the major megatrends in technology that applies worldwide including in Malaysia. Current advantages and expectations of using a connected device has become a reason to use applications in many areas, including the field of retail industry. The evolvement of technology has changed the retail landscape that replaces the manpower in their operations to improve the efficiency, quality and work ethics. Hence, this paper discussed comparative study of technology innovation applied and process flow in unmanned store from different country. Next, prototype of unmanned store apps was designed according to the most preferred technology based on the comparative study. IoT retailer model can be used to improve the retail experience for the customers. Thus, it may perform strategic marketing and gain retail intelligence. Besides, the revolution of using technology in this retail industry is contributing towards Industry 4.0 through digital transformation.
\end{abstract}

Copyright $\odot 2020$ Institute of Advanced Engineering and Science. All rights reserved.

\section{Corresponding Author:}

Saidatul Rahah Hamidi,

Faculty of Computer and Mathematical Sciences,

Universiti Teknologi MARA (UiTM),

40450, Shah Alam, Selangor, Malaysia.

Email: rahah@tmsk.uitm.edu.my

\section{INTRODUCTION}

Recently, new technologies and modalities have changed the nature of work over time that gave greatly impact in global economy. Most changes and magnitudes are varies significantly from industry to industry. In recent years, the development of industrial development has changed shape through the industrial revolution that began with mechanization with water power and steam power. It was later switched to a second industrial revolution which used massive industrial production using the production line and electricity. The third change in the industrial revolution is related to the digital revolution, the use of electronics and IT which is the primary purpose of no other and not to further automate the production. As it is now turning to Industry 4.0 [1]. Industry 4.0 or originally named "Industrie 4.0" begins where its origins are from Germany. It started in early 2010 and based on cyber-physical systems (CPS) [2]. Industry 4.0 involved digital transformation that describe the future of industry [3]. The advent of Industry 4.0 has been boom development of internet of things (IoT). IoT is meant as an information infrastructure around the world where unique physical and virtual images have been identified and linked to the internet which have sparked innovative, sophisticated services, and created a simpler and smarter life [4].

The smart city concept is equipped with various types of electronic devices. Nowadays, the demands for computing resources increased [5]. Therefore, with the use of tools and technologies enable smart city residents to become smarter and make the various technologies in IoT more accessible and usable. Smart order technology, mobile point of sale, and self-scanning checkout are some examples of "contactless technologies" that emerge in retailing process [6]. Hence, electronic transactions, customer experience and 
information integration are some of the components involved in smart retailing [7]. The cost of applying unmanned store is lower as compared to traiditional retail format by leveraging technology [8]. The emergence of IoT in Industrial Revolution 4.0 and Smart City have changed the retail landscape, and gradually replaced human beings. This non-moving department store exemplifies this. Furthermore, optimizing the business model need to focus on cost reduction and improve the effectiveness towards operational benefits on unmmaned retail [9]. Under smart economy, many changes have taken place in line with economic development. The Smart Economy can be divided into innovation, entrepreneurship, trademark, productivity and flexibility of the labor market as well as integration in the national market [10]. This emergent of Smart City and IoT leads to implement Unmanned Store in Malaysia.

\subsection{Unmanned Store}

Unmanned Store can be describe as retail shop that allows shoppers pick and bag their items, without the help of a shop assistant. The cashless payment modes with unified payment system replace the multiple payment terminals [11]. Unmanned Stores are stores using state-of-the-art technology, especially Artificial Intelligence (AI) to replace the workforce in their operations to improve efficiency, saving longterm costs. In some countries, unmanned stores act as an assistant grocery shopping smart start to become popular [12]. It will enable mobile interaction between mobile phone and product. It has now become a global uptrend in the number of out-of-work shops as demonstrated by the launch of Amazon Go in the U.S., 7-Eleven Signatures in South Korea, and Regi-robo in Japan [13]. This topic is to implement new method of business transaction in Malaysia by rebranding new methods of brick and mortar grocery store.

The existence of an unmanned shop has begun since 2016. The store's growth starts with the opening of a store called Naraffar in Sweden dated January 2016. Since then, many unmanned stores opened around the world. These stores can be categorized into two types according to different technologies currently used that include:

a. Self-scanning' on the counter or plate designated to complete the payment before leaving the store.

b. Just walking experience' where customers do not have to pay in the store for the purchase of the product nor do they need to queue up the queue before leaving the store; bills will be settled afterwards;

Comparative study had been done towards selected unmanned stores which implementing the above technologies. The selected unmanned stores are Naraffar from Sweden, Bingobox from China and Amazon Go from America. Discussion of architecture system, technology and implementation method had been studied from the selected stores as below:

\subsubsection{Narrafar}

One of the most innovative countries in the world, Sweden has launched a first unmanned convenience store in the world in 2016. Announced by the end of January 2016 located in the Swedish city of Viken with a population of 4,227 , customers can buy milk, bread, and other retail needs just by using their smartphones. According to the store owner, who is also the founder of this store, Robert Ilijason, a 24-hour store named Naraffar, this store meets the needs of those who need these small items when most supermarkets are usually closed, without the need for staff at all-time [14]. Naraffar is definitely a store without staff; this premise store will be open all year and will be accessible via mobile id app. To buy goods, customers only need to enter the store without going through the user authentication process and will scan their items via the app and then be charged in the end of the month. This store conducts transactions essentially combining two systems which are Sweden BankID apps and Narrafar apps [15].

\subsubsection{Bingobox}

The company named Auchan under a Sun-based France-based Sun Art Retail Group Ltd. has opened a cashless convenience store known as Bingo Box in the Yangpu district of Shanghai in June 2017. Until the last information received at Sep 28, 2017, it has been confirmed that about 158 Bingobox branch units have been opened across China [16]. Moreover, a major innovation in this new retail format is that buyers can complete the entire shopping process from purchase to payment independently without the presence of staff in the store. WeChat is being used by customer to open the door next pay by phone using Alipay (Alibaba's mobile app) and WeChat [17].

\subsubsection{Amazon Go}

Amazon Go is a prototype retail store owned by a popular online retailer, Amazon. There is a change in distribution industry due to ongoing advancement of information and communication technology (ICT) that involve Internet of Things (IoT) [18]. The first prototype store was opened on December 5, 2016 located at the tower of Amazon Tower II in Seattle, Washington. Amazon Go is a store that almost all deals are automatic, with customers able to buy products without using a cashier or checkout station [19]. 
In a report on Amazon Go's opening in the Wall Street Journal, they reported that this first location was one of at least three Amazon's planned to be opened, each in a different format as a prototype for experimental purposes [20]. In October 2016, Business Insider reported that they had seen Amazon's confidential documents describing Amazon to open two thousand stores in the next ten years. They also predict that Amazon may open twenty stores or more, in the next two years [21]. Table 1 above shows the comparison between the three stores according to characteristics of the similarities and differences technology.

Table 1. Comparison Existing Unmanned Stores

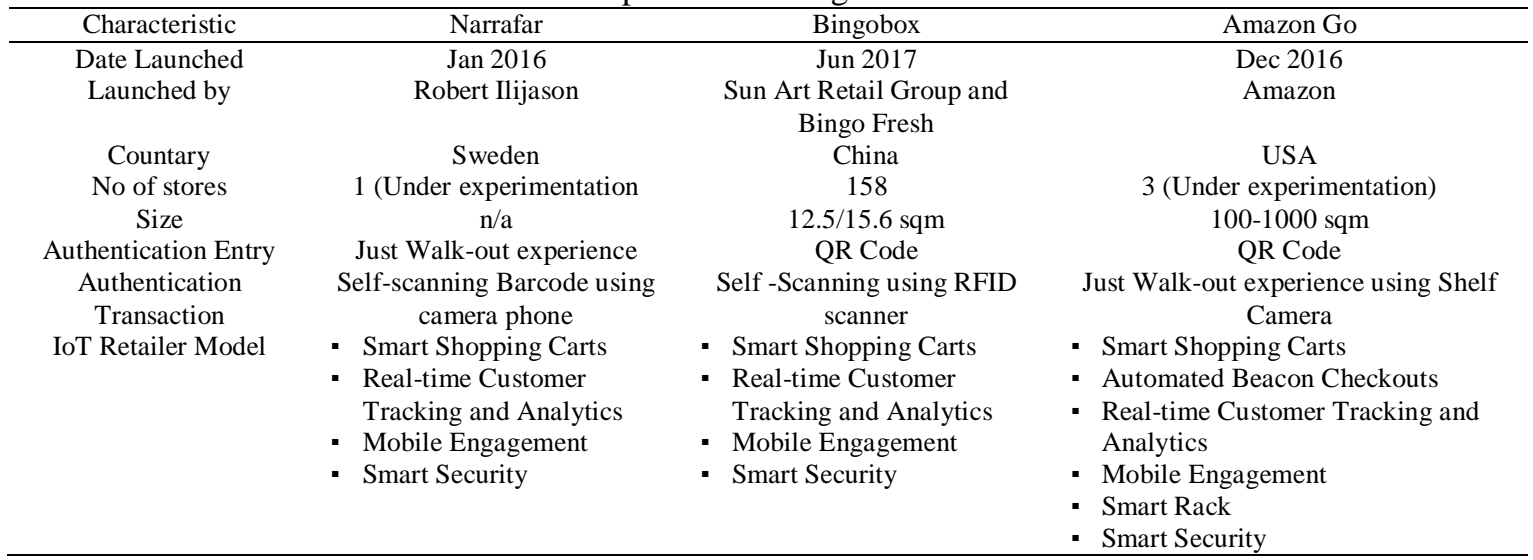

For example, both AmazonGo and Bingobox use the same authentication method that is QR Code. Meanwhile, Naraffar implement 'just walk-out experience' for authentication entry. In terms of safety, all three stores use CCTV cameras. However, only Bingobox has opened branches of 158 branches even it just started from 2017 as compared to others which are still under observation. The most sophisticated technology in transaction processing that is more convenient for humans had been used by AmazonGo. Meanwhile, Naraffar implement barcode scanning technology using mobile, but rather slow as compared to the others because customers shall need to scan each item at a time. RFID technology is applied in Bingobox, for authentication transaction. Customers just have to put things on the scanner and automatically display the price list. In terms of cost, AmazonGo uses higher costs to open a store because it uses a lot of the latest technology. As for the effectiveness, Bingobox is ahead of the rest as it has successfully opened many branches and their working methods keep customers easy.

Consequently, design unmanned store retailer model will be proposed for Malaysia perspective. The retail store may not require staffing on duty for 24 hours and people do not even have to bring the money to enter the grocery store. The customer may perform service without attendant or employee by interacting with self-service technology [22]. Mobile barcode scanning application named Scan It, is a tool that offer customers better shopping experiences to purchase products in supermarket [23]. Innovation from the existing unmanned store, it can be introduced in Malaysia as one of the ways in which the country goes to Smart City. This innovation can be presented to the government, investors or retailer owners to increase the quality of the store in line with the world's progress in Industry 4.0.

\subsection{Security for Online Banking in Malaysia}

Online banking is one of the most important elements in unmanned store. This is because payment method using mobile application and IoT device is payment wave or internet banking. The history of internet banking services has been operating in Malaysia since 2001. At that time, only banking institutions licensed under the Banking and Financial Institutions Act 1989 (BAFIA) and the Islamic Banking Act 1983 were allowed to run Internet Banking services in Malaysia [24]. Nowadays, the nature of the attacks is stronger and more active. Hackers are increasingly brilliant to manipulate the internet. Here are some techniques used by today's attackers stated by Zin et. al. [24]:

a. Trojan Attack. The attacker installed a Trojan, such as key logger program, on a user's computer. This happens when users visited certain websites and downloaded programs.

b. Man-in-the-Middle Attack. Here, the attacker creates a fake website and catches the attention of users to that website.

There are several methods of ensuring a more secure Internet banking stated by Zin et. al. [24]: 
a. Minimum Requirement: Two factor authentications should be implemented in order to verify the authenticity of the information pertaining to Internet banking services. The first authentication factor can be the use of passwords and the second authentication factor can be the use of tokens such as a smartcard. MyKAD is a good avenue to introduce the second factor.

b. Additional requirement: The third authentication factor is the use of biometric such as iris or thumbprint recognition or $\mathrm{QR}$ code.

Our previous work, we surveyed 384 respondents based on the five facets of perceived risk of Internet Banking adoption [18]. Performance risk perceived as the highest risk of using mobile banking as 'Mobile Banking services may not perform well because of network problems' [25]. Nevertheless, information security awareness is important and can be fundamentally impact to integrity, confidentiality and availability of business information [26]. Besides, financial institution should focus on employees training and awareness program in order to enhance the security policy compliance [27] which is very important element as a payment policy in the unmanned store.

\section{SYSTEM DESIGN}

This proposed Unmanned Store in Malaysia will include the illustration design which is named as "Dook". Refer to the Figure 1 for an illustration of the situation process flow in the store design. This Dook store design was designed after identifying, comparing, reviewing the existing Unmanned Store system which is Naraffar at Sweden, Bingobox at China and Amazon Go at United States. This system starts when the user enters the store by scanning the QR code on the barrier, after the user successfully enters the store, the user will be given the opportunity to select the desired item, and will go to the exciting Kiosk to place the selected item on the RFID scanner to scan the item, and next will be displayed a list of items as well as the total price. The RFID scanner will read a lot of prices and a list of items at any one time. After that Kiosk will ask the user to scan the QR code for user authentication. Once successful, the kiosk will prompt the user to enter the keyword to complete the transaction. After the user completes the payment, the user can stay out of the store via alarm beams and flap barrier. If any item passes through an alarm beam without payment, the alarm will ring and the user will not pass the barrier to exit of the store. The store also has a CCTV to observe consumer movements and store conditions in case unexpected condition happened. The shop will provide with a call center phone if the user having problem with the transaction.

Among the features available in this application are Smart Shopping Carts, Mobile Engagement, Smart Security which meets IoT criteria. It is hoped that with the development of this application it will enable Malaysians towards the standard of Smart City which can improve their standard of living.

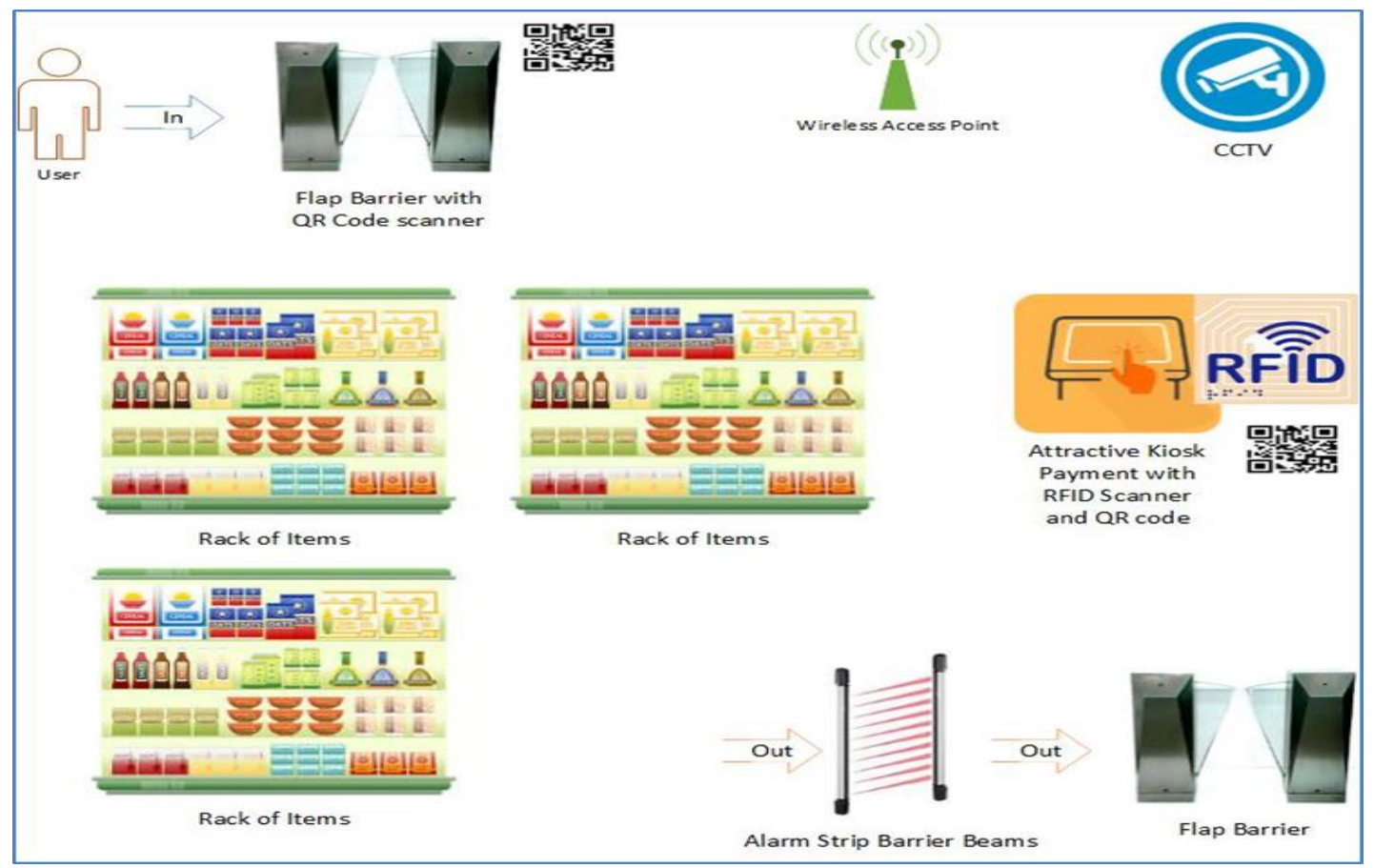

Figure 1. Overview design of dook store 


\section{DOOK: PROTOTYPE OF UNMANNED STORE}

This prototype application was developed after identifying, comparing, reviewing the existing Unmanned Store system. Table 2 shows the features in the Dook application. For this prototype, there are two modules namely authentication entry and authentication transaction using QR code technology.

Table 2. Features of Dook Application

\begin{tabular}{ll}
\hline \multicolumn{1}{c}{ Features } & \multicolumn{1}{c}{ Technology } \\
\hline - Authentication Entry & - QR Code \\
- Authentication & - Passcode \\
- Transaction & - and QR code \\
- Compuage & - Java \\
\hline
\end{tabular}

\subsection{Authentication Module}

Authentication entry module is the module to perform scanning method for patrons who want to enter the store using QR code in this Unmanned Store project. To enter the store, users will receive a dynamic QR code after successfully register in the system. The QR code is dynamic code that allows user to generate new QR code if they lose the QR code. Users can scan QR code to enter the store without having to access the Dook app as long as user have image of QR code. The system will identify the user who has done the verification process. Figure 2 is a screenshot of Dook apps for authentication module.
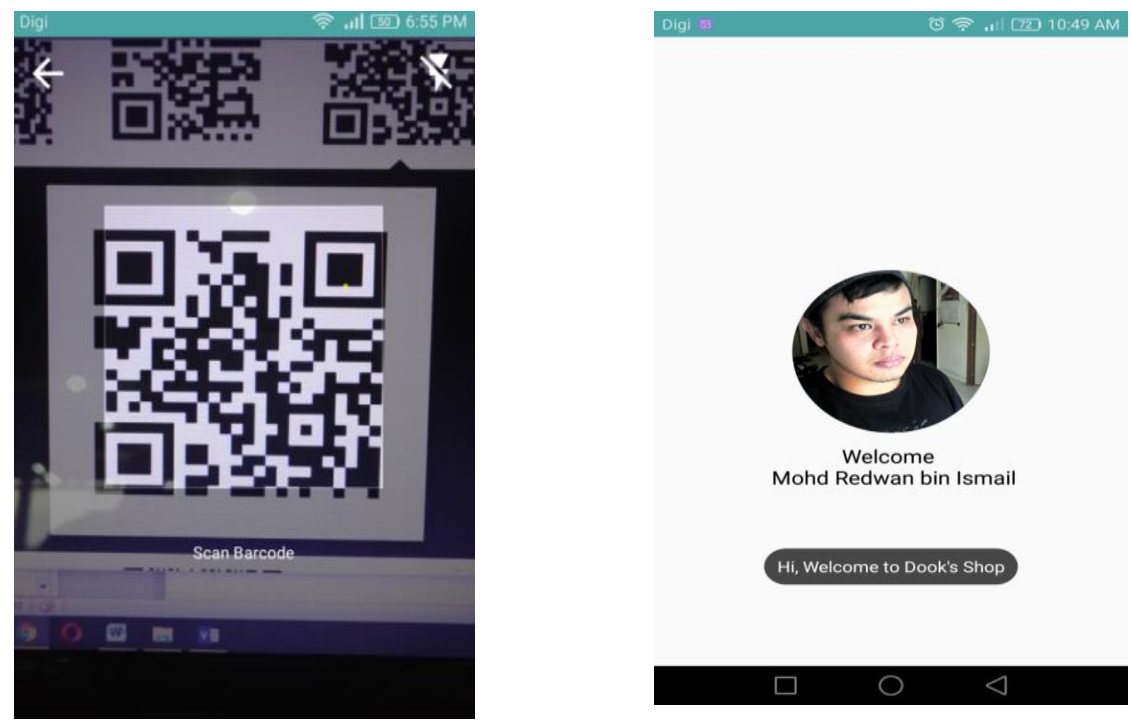

Figure 2. Dook authentication process via QR code

\subsection{Transaction Module}

Module transaction is a module to complete the transaction once the user successfully enters the store. Once the user selects the desired item, the user needs to scan the item on the RFID scanner. But for this prototype application, users only need to choose items as in ordinary e-commerce applications, which need to choose and will go to the shopping cart. This is because RFID scanners unable to be tested because of lack of time and money. After that, the user should scan the QR code for self-verification scan. Once the user is identified, the user needs to enter the passcode to complete the transaction. Figure 3 below is a screenshot of Dook apps for transaction module. 


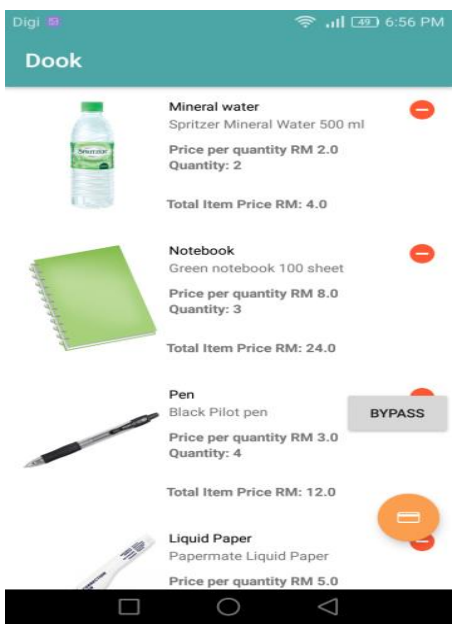

Shopping Cart of Dook Apps

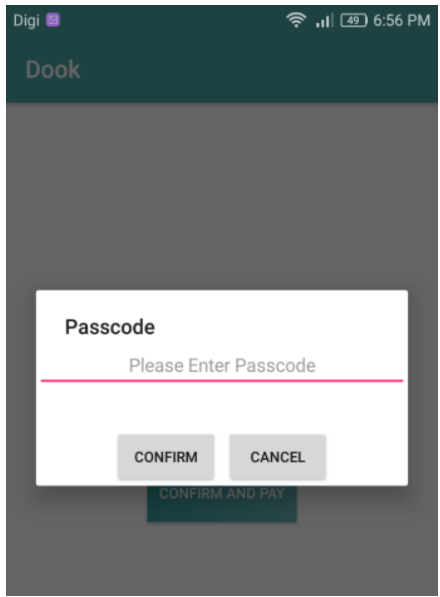

Passcode required completing the transaction

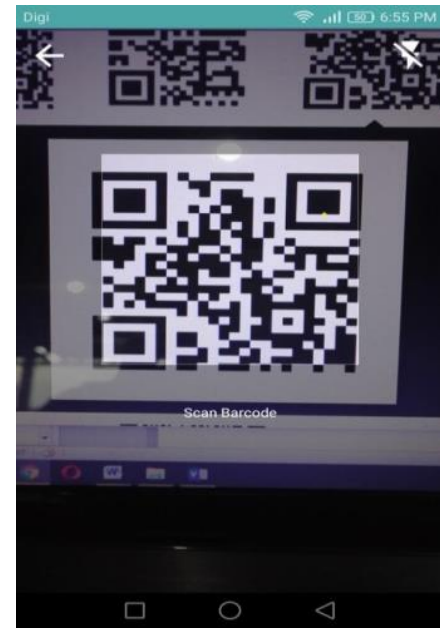

Scanning QR code to authenticate user for transaction

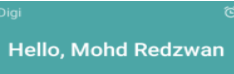

Total Amount: RM 55.0 CONFRM AND PAV

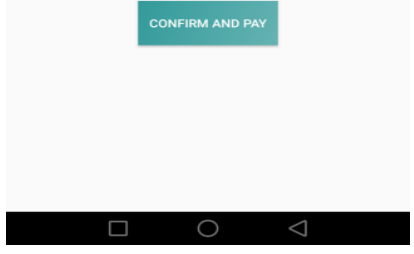

Confirmation of transaction

Figure 3. Dook Transaction Process Flow

\section{CONCLUSION}

Thru this research, few types of Unmanned Store around the world that currently available had been discussed. Next, from the comparative study of Unmanned Store technologies, QR Code and RFID tag had been suggested to be the best combinations to implement Unmanned Store in Malaysia. Besides that, the use of passcode in transaction module gives benefit of security to this system compare to existing Unmanned Store. Unmanned store can be a good example of evolution of retailing to prove an online and offline integration link which links offline stores with mobile apps, state-of-the-art technology and great data. This allows users to get the shopping experience offline but everything is online. Dook Apps are developed through the study of different types of Unmanned Store technologies. It is hope that new retailer model shall improve people standard of living which next contributing towards Smart City. People will able to transform the brick-and-mortar shopping experience by eliminating the checkout line, saving customer time and furthering the company's reputation for convenience.

\section{ACKNOWLEDGEMENTS}

The authors gratefully acknowledge the financial grant 600-IRMI/Dana KCM 5/3/Lestari (156/2017) given by IRMI, Universiti Teknologi MARA, Malaysia and Faculty of Computer and Mathematical Sciences for all supports and resources. 


\section{REFERENCES}

[1] I. A. Al-Homoudi, J. Thakur, R. Naik, G. Auner, and G. Newaz, "Anatase TiO2 films based CO gas sensor: Film thickness, substrate and temperature effects," Applied Surface Science, vol. 253, no. 21, pp. 8607-8614, 2007.

[2] D. Lukac, "The fourth ICT-based industrial revolution 'Industry 4.0'-HMI and the case of CAE/CAD innovation with EPLAN P8," 2015 23rd Telecommunications Forum Telfor (TELFOR), 2015.

[3] S. R. Hamidi, A. A. Aziz, S. M. Shuhidan, A. A. Aziz, and M. Mokhsin, "SMEs Maturity Model Assessment of IR4.0 Digital Transformation," Advances in Intelligent Systems and Computing Proceedings of the 7th International Conference on Kansei Engineering and Emotion Research 2018, pp. 721-732, 2018.

[4] "The Internet of Things (The MIT Press Essential Knowledge Series) 20161 Edited by Samuel Greengard The Internet of Things (The MIT Press Essential Knowledge Series) Cambridge, MA The MIT Press 2015210 pp. 978-0-262-52773-6 £10.65 soft cover," Online Information Review, vol. 40, no. 3, pp. 449-450, 2016.

[5] A. S. Idris, N. Anuar, M. M. Misron, and F. H. M. Fauzi, "The readiness of Cloud Computing: A case study in Politeknik Sultan Salahuddin Abdul Aziz Shah, Shah Alam," 2014 International Conference on Computational Science and Technology (ICCST), 2014.

[6] D. B. Sandarenko, \& A. Pestek. Chapter Ten Safety Issues of Low Energy Micro-Location Technology in Retailing. Trade Perspectives in the Context of Safety, Security, Privacy and Loyalty, 251, 2019.

[7] A. J. Trappey, C. Trappey, W. Wang, and H. I. Hsieh, "Patent Analysis of Key Technologies for Smart Retailing and their Projected Economic Impact," 2018 IEEE 22nd International Conference on Computer Supported Cooperative Work in Design ((CSCWD)), 2018.

[8] Y. Zheng and Y. Li, "Unmanned Retail's Distribution Strategy Based on Sales Forecasting," 2018 8th International Conference on Logistics, Informatics and Service Sciences (LISS), 2018.

[9] L. Zhao and L. Li, "Analysis of Operational Benefits of Unmanned Retail Business Form based on DEA Method," Proceedings of the 2018 International Symposium on Social Science and Management Innovation (SSMI 2018), 2019.

[10] Kagermann, H., Wahlster, W., \& Helbig, J. (2013). "Securing the future of German manufacturing industry". Recommendations for implementing the strategic initiative INDUSTRIE, 4. $\rightarrow$ N. Carvalho, O. Chaim, E. Cazarini, and M. Gerolamo, "Manufacturing in the fourth industrial revolution: A positive prospect in Sustainable Manufacturing,” Procedia Manufacturing, vol. 21, pp. 671-678, 2018.

[11] M. P. R. Bolívar and L. A. Muñoz, "E-Participation in Smart Cities: Technologies and Models of Governance for Citizen Engagement," Public Administration and Information Technology, 2019.

[12] R. Hardasmalani, "Cheers to 'convenience stores of the future'," 28-Jul-2017. [Online]. Available: https://www.todayonline.com/business/cheers-convenience-stores-future. [Accessed: 18-Mar-2018].

[13] K. Hao and K. Hao, "The future of grocery shopping has arrived in China," Quartz, 17-Dec-2017. [Online]. Available: https://qz.com/1157653/jd-com-will-open-hundreds-of-unmanned-convenience-stores/. [Accessed: 25Apr-2018].

[14] C. Weller, "This 24-hour convenience store in Sweden doesn't have a single employee - here's how," Business Insider, 29-Feb-2016. [Online]. Available: http://www.businessinsider.com/swedens-unmanned-convenience-store2016-2/?IR=T. [Accessed: 18-Nov-2018].

[15] Iryna, "Unmanned store is now running in Sweden," 08-Jan-2016. [Online]. Available: https://oresundstartups.com/unmanned-store-is-now-running-in-sweden/. [Accessed: 10-Nov-2018].

[16] S. Millward, "In China, Amazon's 'store of the future' is already open," Tech in Asia - Connecting Asia's startup ecosystem, 04-Jul-2017. [Online]. Available: https://www.techinasia.com/china-version-amazon-go-bingoboxfunding. [Accessed: 20-Mar-2018].

[17] Len Lewis, "Unmanned Stores," The Robin Report, 18-Sep-2018. [Online]. Available: https://www.therobinreport.com/unmanned-stores/. [Accessed: 18-Mar-2019].

[18] S.-H. Lee and D.-W. Lee, "Changes in Distribution Industry Using Information and Communication Technology," Journal Of Advanced Information Technology And Convergence, vol. 8, no. 1, pp. 23-30, 2018.

[19] N. Wingfield, “Amazon Moves to Cut Checkout Line, Promoting a Grab-and-Go Experience,” The New York Times, 22-Dec-2017. [Online]. Available: https://www.nytimes.com/2016/12/05/technology/amazon-moves-to-cutcheckout-line-promoting-a-grab-and-go-experience.html. [Accessed: 08-Jan-2019].

[20] L. Stevens and K. Safdar, "Amazon Working on Several Grocery-Store Formats, Could Open More Than 2,000 Locations," The Wall Street Journal, 06-Dec-2016. [Online]. Available: https://www.wsj.com/articles/amazongrocery-store-concept-to-open-in-seattle-in-early-2017-1480959119. [Accessed: 03-Aug-2018].

[21] B. F. Rubin, "Amazon: No, we're not opening 2,000 stores," CNET, 07-Dec-2016. [Online]. Available: https://www.cnet.com/news/amazon-no-were-not-building-2000-stores/. [Accessed: 18-Mar-2019].

[22] L. Nerlund. "Exploration of how to improve experience by designing a self-service technology.", 2018.

[23] K. D. Othuon.'Improving customer shopping experience using an Android bar-code reader application (Doctoral dissertation, Strathmore University)", 2018.

[24] A. N. M. Zin, \& Z. Yunos. "How to make online banking secure". The Star, 21, 2005.

[25] S. M. Shuhidan, S. R. Hamidi, and I. S. Saleh, "Perceived Risk towards Mobile Banking: A case study of Malaysia Young Adulthood," IOP Conference Series: Materials Science and Engineering, vol. 226, p. 012115, 2017.

[26] J. Kaur and N. Mustafa, "Examining the effects of knowledge, attitude and behaviour on information security awareness: A case on SME," 2013 International Conference on Research and Innovation in Information Systems (ICRIIS), 2013. 
[27] A. I. H. Suhaimi and A. Lokman, "Demographic Profile and Intention to Comply with Security Policy in Financial Institutions in Malaysia," Indian Journal of Science and Technology, vol. 9, no. S1, 2016.

\section{BIOGRAPHIES OF AUTHORS}
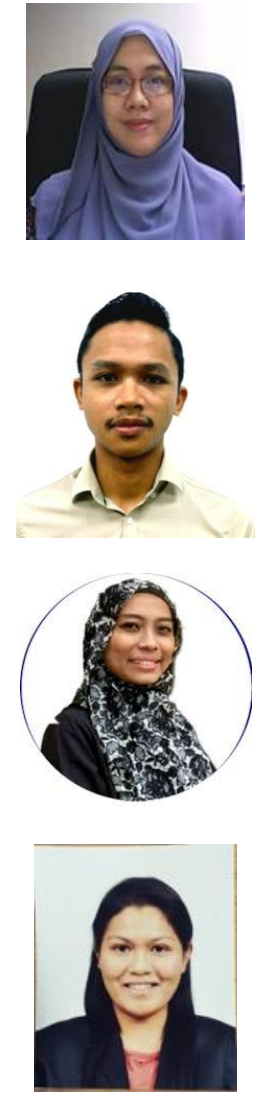

Saidatul Rahah Hamidi is a senior lecturer in Faculty of Computer and Mathematical Sciences. She received a Bachelor of Computer Science with Honours (Industrial Computing) in 2004, and Master of Information Technology-Management (Excellent Masters Award) from Faculty of Computing, UTM Skudai, Johor in 2006. She was a software engineer at Dataprep Holdings Sdn Bhd before joining UiTM as lecturer in 2007. Domain expertise revolved in information and data technology. However, at current embarked into Big Data and Data Analytics research interests with professional certifications in the pipeline.

Muhammad Afiq received his MScIT from MARA University of Technology in 2018. He is currently a senior IT Support in the Department of Technical at V-Series International Sdn Bhd. His research interests include Internet of Things, cloud computing, smart city, information security and technology innovation. He also received his Bachelor's degree in Business Computing from MARA University of Technology in 2013.

Dr. Shuhaida Mohamed Shuhidan is a senior lecturer in Faculty of Computer and Mathematical Science and also a research fellow in Accounting Research Institute. She is also an Accreditation Panel in Financial Accreditation Agency. She received her Doctorate from RMIT University, Australia in 2012. She is actively doing research in Data Analytics, Computing Education and Emotion Intelligence.

Shamsiah Abd Kadir studied at the Faculty of Communication and Media Studies, Universiti Teknologi MARA (UiTM), Malaysia, and received a Bachelor of Mass Communication with Honours (Publishing) in 2008, and Master of Arts (and received Excellent Masters Award) in Media and Information Warfare from Centre for Media and Information Warfare Studies, UiTM in 2013. Currently, she is pursuing her PhD (specifically in Mathematical Politics), also in Media and Information Warfare at the same university. Prior to enrolling her PhD at UiTM, Shamsiah was an Assistant Editor and Journalist for one of the local magazines that covers social, politics and economics issue/domain in Malaysia, with more than 6 years of experience. She has interests in Media Warfare, Politics, Kansei Engineering, Internet and Social Media. Several papers under her research have been accepted by various journals for publication, presented in international conferences and have received various peer reviews. She is also an active member of the Malaysia Association of Kansei Engineering (MAKE). 